\title{
Enhanced Symbiotic Organisms Search (ESOS) for Global Numerical Optimization
}

\author{
Doddy Prayogo \\ Dept. of Civil Engineering \\ Petra Christian University \\ Surabaya, Indonesia \\ prayogo@petra.ac.id
}

\author{
Foek Tjong Wong \\ Master Program of Civil Engineering \\ Petra Christian University \\ Surabaya, Indonesia \\ wftjong@petra.ac.id
}

\author{
Steven Sugianto \\ Master Program of Civil Engineering \\ Petra Christian University \\ Surabaya, Indonesia \\ m01516011@john.petra.ac.id
}

\begin{abstract}
Symbiotic organisms search (SOS) is a simple yet effective metaheuristic algorithm to solve a wide variety of optimization problems. Many studies have been carried out to improve the performance of the SOS algorithm. This research proposes an improved version of the SOS algorithm called the "enhanced symbiotic organisms search" (ESOS) for global numerical optimization. The conventional SOS is modified by implementing a new searching formula into the parasitism phase to produce a better searching capability. The performance of the ESOS is verified using 26 benchmark functions and one structural engineering design problem. The results are then compared with existing metaheuristic optimization methods. The obtained results show that the ESOS gives a competitive and effective performance for global numerical optimization.
\end{abstract}

Keywords-metaheuristic algorithm, symbiotic organisms search, global numerical optimization, structural engineering design

\section{INTRODUCTION}

In the last few decades, global numerical optimization has become an interesting and challenging field of study to develop. Many of the optimization problems were solved by gradient-based optimization methods. However, technology has advanced rapidly in the last few decades, causing optimization problems to be varied and difficult to resolve. As a result, gradient-based optimization methods become less efficient in solving some complex problems. Due to these limitations, researchers have sought to find other optimization methods that are more effective than gradient-based optimization methods.

Recently, numerous metaheuristic optimization methods have been extensively researched and have evolved into potential alternatives to gradient-based methods. A "metaheuristic" is defined as an algorithmic framework that has a particular pattern, often nature-inspired, that iteratively simulates a set of randomly generated solutions to achieve better optimal solutions [1]. Notable examples of metaheuristic algorithms include the genetic algorithm (GA) [2], simulated annealing (SA) [3], particle swarm optimization (PSO) [4], differential evolution (DE) [5], ant colony optimization (ACO) [6], harmony search (HS) [7], artificial bee colony $(\mathrm{ABC})$ [8], firefly algorithm (FA) [9], cuckoo search (CS) [10], and teaching-learning-based optimization (TLBO) [11].

However, there are limitations of existing metaheuristic methods. For example, GA uses complicated operators (on selection and crossover), often trapped in local optima, and has a weak local search capability [12]. PSO has a poor exploration capability in solving complex multimodal problems and can be easily trapped in local optima [12]. As a result, in agreement with the "no-free-lunch" theory [13], new metaheuristic optimization methods must be developed to solve specific and more complex optimization problems [1416]. Furthermore, there is a growing number of studies in combining metaheuristic algorithms with other techniques to handle advanced problems [17-20].

Symbiotic organisms search (SOS) proposed by Cheng and Prayogo [21] is a promising new metaheuristic method that can produce a better solution in comparison with other traditional metaheuristic methods such as GA, PSO, and DE. This method simulates symbiotic behaviors between living creatures of different species in an ecosystem with the goal of survival. Although quite new, SOS has been utilized to solve many difficult optimization problems. In this research, an improved version of SOS is proposed called "enhanced symbiotic organisms search" (ESOS), which modifies the mechanism of the parasitism phase to produce a better exploration strategy. The proposed ESOS method is then used to solve complicated mathematical benchmark problems and one structural engineering design problem.

\section{Methodology}

\section{A. Brief Introduction to the SOS Algorithm}

First developed by Cheng and Prayogo [21], SOS is a metaheuristic algorithm inspired by the symbiotic relationships among organisms in their ecosystem as illustrated in Fig. 1. Initially developed for continuous numerical optimization, SOS has been widely used for solving various optimization problems in a variety of research areas. Similar to well-known metaheuristic algorithms, SOS comprise a sequence of operations that can generate potential best solutions at each iteration. 


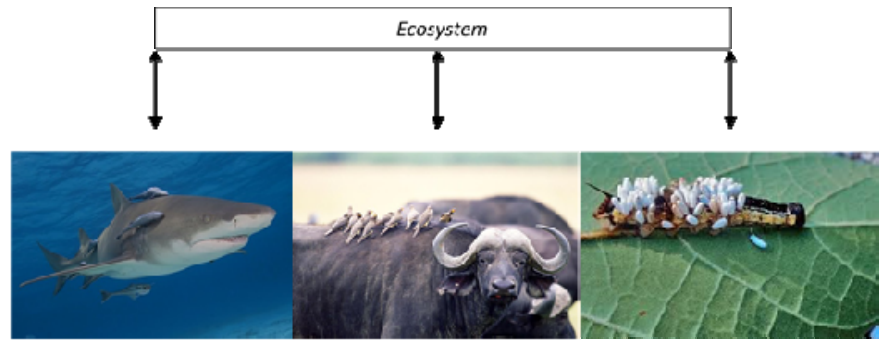

Fig. 1. Illustrations of symbiotic mutualism, commensalism, and parasitism.

The algorithm is constructed in three main phases: mutualism, commensalism, and parasitism. In the mutualism phase, two candidate solutions benefit from the interaction; in the commensalism phase, one of the candidates receives an advantage while the other candidate is not affected; and in the parasitism phase, one candidate benefits while the other is harmed. The cycle of these symbiotic interactions continues until the specific criteria are satisfied.

\section{B. Modification in the SOS Algorithm}

Since its introduction by Cheng and Prayogo [21], SOS has been widely applied in many research fields [22-26]. The three phases that comprise the SOS structure offer unique searching characteristics [21]. For example, mutualism and commensalism benefit SOS with their good exploration capabilities, and parasitism has a strong exploiting characteristic with its cloning and random-based mutation operator. Additionally, parasitism has the capability to remove inferior solutions. Nevertheless, improving the performance of SOS has become even more necessary as the complexity of numerical problems has increased tremendously.

In this research, enhanced SOS (ESOS) is introduced as an improved version of SOS by modifying the current parasitism phase. In addition to the commonly known cloning and mutation concept, a sub-phase, called "cleptoparasitism" is introduced in the parasitism phase. The proposed sub-phase is originally adopted from the crow search algorithm (CSA) [27]. The cleptoparasitism sub-phase mimics the ingenious behavior of crows that keep their food reserves in hiding places for future retrieval. The following pseudo-code explains the mechanism of the modified parasitism phase:

1: Generate a uniform random number, rand1, between $[0,1]$

2: $\quad$ if rand $1<0.5$ then

3: $\quad / *$ parasitism sub-phase */

4: Generate parasite_vector

5: $\quad$ Evaluate its fitness value

6: Select the fittest organism between parasite_vector and its host

7: $\quad$ elseif rand $1>0.5$ then

8: $\quad$ /* cleptoparasitism sub-phase */
Select the fittest organism between cleptoparasite_vector and its host

12: $\quad$ end if

\section{3: end for}

Similar to the canonical SOS, the ecosystem passes through the mutualism and commensalism phases in sequence before entering the modified parasitism phase. The modified parasitism phase is now of two sub-phases: the original parasitism sub-phase and the cleptoparasitism sub-phase.

In the cleptoparasitism sub-phase, $r i$ is introduced as a uniform random number with a value determined by Askarzadeh [27], as seen in (1):

$$
\operatorname{ri}=\operatorname{rand}(0,1)
$$

Thereafter, $f l$ is the range of the range between the $m$ organism and $(m+1)$-organism in a single loop. The value of $f l$ is determined by the user taking a random number with a uniform distribution between -2 and 2 . There is a possibility of random numbering for $f l$ that results in better search performance, but the researcher has not done so due to time constraints. The definition of $f l$ can be seen in (2):

$$
f l=\operatorname{rand}(-2,2)
$$

The coef is the coefficient of the difference in value possessed by the best position of organism $\left(x_{\text {best }}\right)$ and the current position of the $m$-organism $\left(x_{m}\right)$, which can be seen in (3); and the new position of the $m$-organism $\left(x_{m}{ }^{\prime}\right)$ obtained through (4):

$$
\begin{gathered}
\text { coef }=r i \times f l \\
x_{m}^{\prime}=x_{m}+\operatorname{coef}\left(x_{b e s t}-x_{m}\right)
\end{gathered}
$$

\section{ESOS VALIDATION ON NUMERICAL BENCHMARK PROBLEMS}

In this section, the performance of ESOS is tested through complex benchmark problems. For comparison purpose, PSO, $\mathrm{DE}$, and the original SOS algorithm are employed. The experimental setting is described as follows: the population sizes of PSO, DE, SOS, and ESOS are set to 50 each; the maximum number of function evaluations is set to be 250,000; and the iteration stops only if the function evaluations exceed the maximum number allowed.

To maintain an equivalent comparison, PSO, DE, SOS, and ESOS algorithms are tested under the same conditions and 
parameter settings for the four algorithms as shown in Table I. The number of ecosystems is denoted by $n ; w$ is the inertia weight; $c$ is the crossover rate; and $F$ is the scaling factor. A set of 26 benchmark functions is used to evaluate the algorithms. The experiment is repeated over 30 times and the average results for mean (M) and standard deviation (SD) are recorded in Table II and Table III. Bolded numbers represent the best mean value for each function.

TABLE I. Parameter SETtings For Numerical BENCHMARK PROBLEMS

\begin{tabular}{|c|c|}
\hline PSO & $n=50, w=1, c_{l}=2, c_{2}=2$ \\
\hline DE & $n=50, F=0.4, c=0.5$ \\
\hline SOS & $n=50$ \\
\hline ESOS & $n=50$ \\
\hline
\end{tabular}

TABLE II. COMPARISON OF ANALYSIS BETWEEN ESOS AND OTHER METAHEURISTICS (F1-F13)

\begin{tabular}{|c|c|c|c|c|c|c|}
\hline \multicolumn{2}{|c|}{ Functions } & Min. & PSO & DE & sos & ESOS \\
\hline \multirow{2}{*}{ F1-Beale } & M & 0 & 0.00049 & 7245.70 & 0 & 0 \\
\hline & SD & & 0.00075 & 0 & 0 & 0 \\
\hline \multirow{2}{*}{ F2-Easom } & M & -1 & -0.9263 & -1 & -1 & -1 \\
\hline & SD & & 0.05701 & 0 & 0 & 0 \\
\hline \multirow{2}{*}{ F3-Matyas } & M & 0 & $5.39 \mathrm{E}-05$ & 4.90 & o & o \\
\hline & SD & & $5.54 \mathrm{E}-05$ & 0 & 0 & 0 \\
\hline \multirow{2}{*}{$\begin{array}{c}\text { F4- } \\
\text { Boachevsky1 }\end{array}$} & M & 0 & 0.41971 & $9.3 \mathrm{E}-17$ & $\mathbf{0}$ & 0 \\
\hline & SD & & 0.22651 & $1.1 \mathrm{E}-16$ & 0 & 0 \\
\hline \multirow{2}{*}{ F5-Booth } & M & 0 & 0.01673 & 76.97 & 0 & 0 \\
\hline & SD & & 0.01671 & 63.50 & 0 & 0 \\
\hline \multirow{2}{*}{$\begin{array}{c}\text { F6- } \\
\text { Michalewicz2 }\end{array}$} & $\mathrm{M}$ & -1.8013 & -1.8002 & -0.8013 & -1.8013 & -1.8013 \\
\hline & SD & & 0.00126 & $3.4 \mathrm{E}-16$ & 9.03E-16 & $9.03 \mathrm{E}-16$ \\
\hline \multirow{2}{*}{ F7-Schaffer } & M & 0 & 0.03034 & 0.0487 & 0 & o \\
\hline & SD & & 0.01538 & 0.19061 & 0 & 0 \\
\hline \multirow{2}{*}{$\begin{array}{l}\text { F8-Six Hump } \\
\text { Camel Back }\end{array}$} & $\mathrm{M}$ & -1.03163 & -1.0310 & 0.0082 & -1.03163 & -1.03163 \\
\hline & SD & & 0.00090 & $9.0 \mathrm{E}-10$ & $6.78 \mathrm{E}-16$ & $6.78 \mathrm{E}-16$ \\
\hline \multirow{2}{*}{$\begin{array}{c}\text { F9- } \\
\text { Boachevsky2 }\end{array}$} & M & 0 & 0.25366 & $1.1 \mathrm{E}-17$ & 0 & o \\
\hline & SD & & 0.19874 & $2.3 \mathrm{E}-17$ & 0 & 0 \\
\hline \multirow{2}{*}{$\begin{array}{c}\text { F10- } \\
\text { Boachevsky3 }\end{array}$} & M & 0 & 0.24715 & $1.9 \mathrm{E}-16$ & 0 & 0 \\
\hline & SD & & 0.15172 & $2.2 \mathrm{E}-16$ & 0 & 0 \\
\hline \multirow{2}{*}{ F11-Shubert } & $\mathrm{M}$ & -186.73 & -186.63 & 189.57 & -186.73 & -186.73 \\
\hline & SD & & 0.12542 & 22.74 & 4.70E- 08 & $3.95 \mathrm{E}-14$ \\
\hline \multirow{2}{*}{ F12-Colville } & $\mathrm{M}$ & 0 & 7.44825 & 23.29 & $9.64 \mathrm{E}-12$ & $2.07 \mathrm{E}-12$ \\
\hline & SD & & 3.95789 & 118.28 & $1.19 \mathrm{E}-11$ & $4.30 \mathrm{E}-12$ \\
\hline \multirow{2}{*}{$\begin{array}{c}\text { F13- } \\
\text { Michalewicz5 }\end{array}$} & $\mathrm{M}$ & -4.6877 & -3.5903 & -2.24 & -4.6877 & -4.6877 \\
\hline & SD & & 0.22732 & $2.9 \mathrm{E}-08$ & $2.27 \mathrm{E}-15$ & $1.51 \mathrm{E}-15$ \\
\hline
\end{tabular}

TABLE III. COMPARISON OF ANALYSIS BETWEEN ESOS AND OTHER METAHEURISTICS (F14-F26)

\begin{tabular}{|c|c|c|c|c|c|c|}
\hline \multicolumn{2}{|c|}{ Functions } & Min. & PSO & DE & sos & ESOS \\
\hline \multirow{2}{*}{ F14-Zakharov } & $\mathrm{M}$ & 0 & 9.73168 & $5.3 \mathrm{E}-83$ & 7.4E-247 & $1.6 \mathrm{E}-254$ \\
\hline & SD & & 5.61788 & $1.8 \mathrm{E}-82$ & 0 & 0 \\
\hline \multirow{2}{*}{$\begin{array}{c}\text { F15- } \\
\text { Michalewicz10 }\end{array}$} & M & -9.6602 & -5.1983 & -3.2790 & -9.65588 & -9.65711 \\
\hline & $\mathrm{SD}$ & & 0.32766 & $1.0 \mathrm{E}-07$ & 0.012404 & 0.015359 \\
\hline \multirow{2}{*}{ F16-Step } & M & 0 & 2014.11 & $3.4 \mathrm{E}-18$ & $1.64 \mathrm{E}-33$ & $1.34 \mathrm{E}-33$ \\
\hline & SD & & 2009.55 & $1.9 \mathrm{E}-17$ & $4.11 \mathrm{E}-33$ & $3.20 \mathrm{E}-33$ \\
\hline \multirow{2}{*}{ F17-Sphere } & M & 0 & 2343.93 & $4.8 \mathrm{E}-67$ & $\mathbf{0}$ & $\mathbf{0}$ \\
\hline & SD & & 1948.64 & $2.6 \mathrm{E}-66$ & 0 & 0 \\
\hline \multirow{2}{*}{$\begin{array}{l}\text { F18-Sum } \\
\text { Squares }\end{array}$} & M & 0 & 364.59 & $7.8 \mathrm{E}-32$ & $\mathbf{0}$ & $\mathbf{0}$ \\
\hline & SD & & 266.11 & $4.2 \mathrm{E}-31$ & 0 & 0 \\
\hline \multirow{2}{*}{ F19-Quartic } & M & 0 & 2.26620 & 6.2081 & 0.000205 & 0.000185 \\
\hline & SD & & 1.78097 & 4.68605 & $7.51 \mathrm{E}-05$ & 8.47E-05 \\
\hline \multirow{2}{*}{$\begin{array}{c}\text { F20-Schwefel } \\
\quad 2.22\end{array}$} & M & 0 & 21.17 & $1.1 \mathrm{E}-66$ & $\mathbf{0}$ & $\mathbf{0}$ \\
\hline & $\mathrm{SD}$ & & 8.10003 & $1.7 \mathrm{E}-66$ & 0 & 0 \\
\hline \multirow{2}{*}{$\begin{array}{c}\text { F21-Schwefel } \\
1.2\end{array}$} & $\mathrm{M}$ & 0 & 27564.87 & $4.5 \mathrm{E}-19$ & o & $\mathbf{0}$ \\
\hline & SD & & 22372.68 & $2.5 \mathrm{E}-18$ & 0 & 0 \\
\hline \multirow{2}{*}{$\begin{array}{c}\text { F22- } \\
\text { Rosenbrock }\end{array}$} & M & 0 & 428791.9 & 1969.32 & 9.887101 & 0.576513 \\
\hline & $\mathrm{SD}$ & & 556753.5 & 3607.47 & 1.430548 & 0.435882 \\
\hline \multirow{2}{*}{$\begin{array}{l}\text { F23-Dixon- } \\
\text { Price }\end{array}$} & M & 0 & 6415.98 & 15.38 & 0.666667 & 0.666667 \\
\hline & SD & & 13932.88 & 38.31 & $2.50 \mathrm{E}-16$ & 1.13E-16 \\
\hline \multirow{2}{*}{ F24-Rastrigin } & M & 0 & 202.88 & 87.82 & $\mathbf{0}$ & $\mathbf{0}$ \\
\hline & SD & & 54.48 & 36.74 & 0 & 0 \\
\hline \multirow{2}{*}{ F25-Griewank } & $\mathrm{M}$ & 0 & 17.76 & 0.03580 & 0 & 0 \\
\hline & SD & & 13.23 & 0.19608 & 0 & 0 \\
\hline \multirow{2}{*}{ F26-Ackley } & M & 0 & 8.99452 & $8.1 \mathrm{E}-15$ & $4.2 \mathrm{E}-15$ & 3.97E-15 \\
\hline & SD & & 3.05423 & 1.7E-15 & $9.01 \mathrm{E}-16$ & $1.23 \mathrm{E}-15$ \\
\hline
\end{tabular}

To further find out about the superiority of the ESOS compared with the original SOS algorithm, we show the convergence profiles for Rosenbrock mathematical benchmark problem in each iteration as shown in Fig. 2. The SOS algorithm has a slightly better convergence rate in comparison with the ESOS algorithm. However, as the iteration progresses to a greater value, ESOS converges faster. The ESOS and SOS algorithms found the best value of 0.13893 and 4.64578, respectively, after 1200 iterations. This proves that improvisation in one phase of the SOS algorithm produces a positive impact on the computation of more optimal results. 


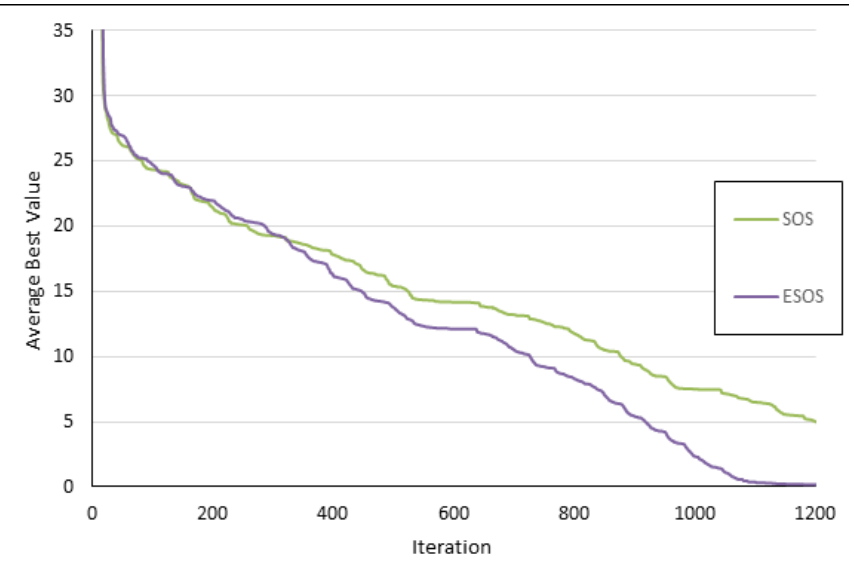

Fig. 2. Convergence profiles for the SOS and ESOS algorithm on Rosenbrock mathematical benchmark problem.

\section{Practical Example of Structural Problem}

Practical performance of the ESOS algorithm is investigated by using 72-bar space truss structure problem. PSO, DE, and SOS algorithms are used as comparisons. For all four methods, the best weight (minimum), standard deviation, and average (mean) were obtained from 30 independent runs, with the maximum value for the function evaluation set at 50,000 .

The objective of the 72-bar space truss problem is to obtain the lightest structural weight and was previously investigated by $\mathrm{Li}$ et al. [28]. This test problem uses two linear inequality constraints, stress $(\sigma)$ and displacement $(\Delta)$, and one design variable, cross-sectional area $(x)$. The following objective of design optimization on structural problem is to find a minimum weight $(W)$ of structures, so we can get a minimum cost of construction. The objective function for this problem can be seen in (5):

$$
W=\sum_{m=1}^{N_{m}} L_{m} m_{m}
$$

with $N_{m}$ is the total number of truss members, $L_{m}$ is the length of each truss members, and $m_{m}$ is the coefficient of weight per length of truss members, as follows:

$$
m_{m}=2.71447 x
$$

The boundary conditions for cross-sectional area of truss $(x)$ can be seen in (7) and the following limitations are the design constraints for structural problem tested, that can be seen in (8) and (9) as follows:

$$
64.52 \leq x \leq 2064.51
$$

$$
g_{m}=\frac{\sigma_{m}}{\left(\sigma_{m}\right) \text { all }}-1 \leq 0 ; m=1,2,3, \ldots, N_{m}
$$

$$
\delta_{j k}=\frac{d_{j, k}}{\left(d_{j, k}\right) \text { all }}-1 \leq 0 ; \mathrm{j}=1,2,3, \ldots, N_{j}
$$

In (8) and (9), $g_{m}$ and $\delta_{j k}$ are the optimization constraints for stress and displacements, respectively. For the $m$-th member, $\sigma_{m}$ is the computed axial stresses and $\left(\sigma_{m}\right)_{\text {all }}$ is its allowable. While for $j$-th joint on the $k$-th direction, $d_{j k}$ is the computed displacements and $\left(d_{j k}\right)_{\text {all }}$ is its allowable, and $N_{j}$ is the total number of joints.

Due to the symmetry of existing structures and according to previous research, these structures are divided into 16 groups of elements. The load case for 72-bar space truss problem is listed in Table IV and the structure is shown in Fig. 3. A performance comparison of the statistical results between ESOS and other metaheuristics is presented as Table V. In this table, bold texts indicate the best results. The ESOS and SOS algorithms achieve the best (minimum) weight of the structure, i.e., 1714.98 N. However, the ESOS algorithm outperforms SOS in best average and standard deviation for the weight of the structure. For best mean and standard deviation, the SOS algorithm achieves, respectively, $1717.95 \mathrm{~N}$ and 4.29 while the ESOS algorithm achieves $1715.90 \mathrm{~N}$ and 2.89.

TABLE IV. LOAD CASE FOR 72-BAR SPACE TRUSS PROBlEM

\begin{tabular}{|c|c|c|c|}
\hline \multirow{2}{*}{ Nodes } & \multicolumn{3}{|c|}{ Load (kg) } \\
\cline { 2 - 4 } & $\boldsymbol{P}_{\boldsymbol{x}}$ & $\boldsymbol{P}_{\boldsymbol{y}}$ & $\boldsymbol{P}_{z}$ \\
\hline 17 & 2267.96 & 2267.96 & -2267.96 \\
\hline
\end{tabular}
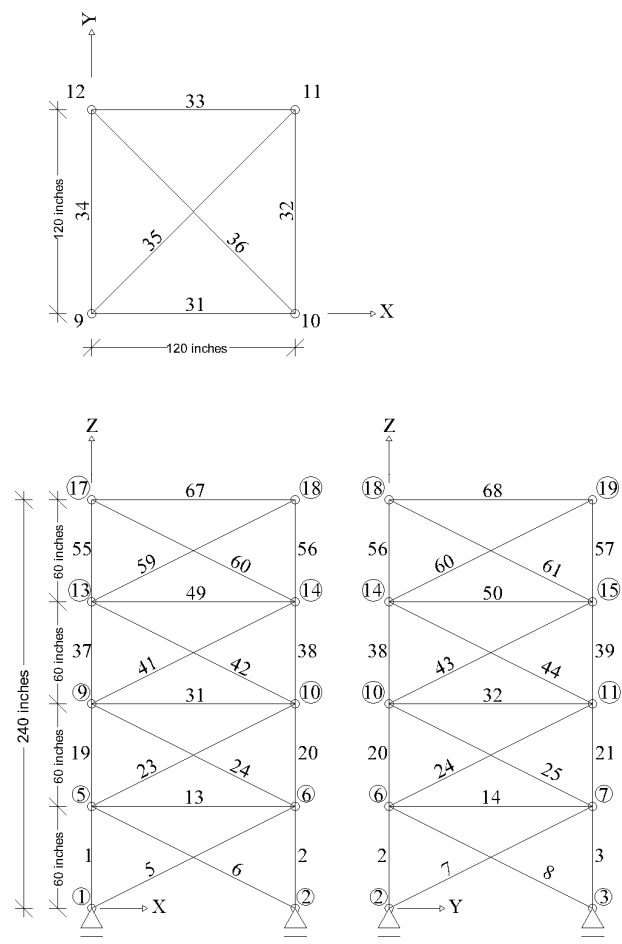

Fig. 3. A 72-bar space truss structure. 
TABLE V. COMPARISON OF STATISTICAL RESUlTS FOR ESOS AND OTHER METAHEURISTICS

\begin{tabular}{|c|c|c|c|}
\hline Algorithms & Best & Mean & St. Dev. \\
\hline PSO & 5510.87 & 7725.08 & 1072.46 \\
\hline DE & 1778.42 & 3193.12 & 990.52 \\
\hline SOS & $\mathbf{1 7 1 4 . 9 8}$ & 1717.95 & 4.29 \\
\hline ESOS & $\mathbf{1 7 1 4 . 9 8}$ & $\mathbf{1 7 1 5 . 9 0}$ & $\mathbf{2 . 8 9}$ \\
\hline
\end{tabular}

\section{CONCLUSIONS}

This research proposes the ESOS method for global numerical optimization. This method modifies the conventional SOS method by implementing a new searching formula in the parasitism phase, with the intention of producing a better searching capability. We compared ESOS performance with PSO, DE, and the original SOS algorithm across 26 benchmark functions and one structural engineering design problem. The computational results and comparisons verify the superiority of ESOS in solving some complex mathematical benchmark problems better than other tested algorithms. Furthermore, for the structural problem, ESOS demonstrated consistent performance to produce optimal solutions. This is confirmed from the smaller standard deviation produced by ESOS compared with other metaheuristic algorithms including SOS. Thus, the implemented improvisation in the parasitism phase produced a large positive impact on the computational results. The ESOS algorithm delivers competitive, superior, and effective performance for global numerical optimization.

\section{REFERENCES}

[1] I. Osman and G. Laporte, "Metaheuristics: A bibliography", Ann. Oper. Res., 1996, 63, (5), pp. 511-623.

[2] J.H. Holland, Adaptation in natural and artificial systems. University of Michigan Press. 1975.

[3] S. Kirkpatrick, C.D. Gelatt, and M.P. Vecchi, "Optimization by Simulated Annealing", Science, 1983, 220, pp. 671-680.

[4] J. Kennedy and R. Eberhart, "Particle swarm optimization". Proc. of IEEE Int. Conf. on Neural Networks, 1995, pp. 1942-1948.

[5] R. Storn and K. Price, "Differential Evolution - A Simple and Efficient Heuristic for global Optimization over Continuous Spaces", J. Global Optim., 1997, 11, (4), pp. 341-359.

[6] M. Dorigo and G.D. Caro, "Ant colony optimization: a new metaheuristic". Proc. of the 1999 Congress on Evolutionary Computation, 1999, pp. 1-1477.

[7] Z.W. Geem, J.H. Kim, and G.V. Loganathan, "A New Heuristic Optimization Algorithm: Harmony Search", Simul., 2001, 76, pp. 6068.

[8] D. Karaboga and B. Basturk, "A powerful and efficient algorithm for numerical function optimization: artificial bee colony (ABC) algorithm", J. Global Optim., 2007, 39, (3), pp. 459-471.

[9] X.-S. Yang, Nature-inspired Metaheuristic Algorithms. Luniver Press. 2008.
[10] X.-S. Yang and S. Deb, "Cuckoo Search via Lévy flights". The World Congr. on Nature and Biologically Inspired Computing (NaBIC'09), 2009, pp. 210-214.

[11] R.V. Rao, V.J. Savsani, and D.P. Vakharia, "Teaching-learning-based optimization: A novel method for constrained mechanical design optimization problems", Comp.-Aided Design, 2011, 43, pp. 303-315.

[12] Z. Beheshti and S.M. Shamsuddin, "A Review of Population-based Meta-Heuristic Algorithm", Int. J. Adv. Soft Comput. Appl., 2013, 5, pp. 1-35.

[13] D.H. Wolpert and W.G. Macready, "No Free Lunch Theorems for Optimization". IEEE Trans. Evol. Comput., 1997, pp. 67-82.

[14] M.-Y. Cheng, D. Prayogo, Y.-W. Wu, and M.M. Lukito, "A Hybrid Harmony Search algorithm for discrete sizing optimization of truss structure", Automat. Constr., 2016, 69, pp. 21-33.

[15] M.-Y. Cheng and D. Prayogo, "A novel fuzzy adaptive teachinglearning-based optimization (FATLBO) for solving structural optimization problems", Eng. Comput., 2017, 33, (1), pp. 55-69.

[16] M.-Y. Cheng and D. Prayogo, "Fuzzy adaptive teaching-learningbased optimization for global numerical optimization", Neural. Comput. Appl., 2016, pp. 1-19.

[17] M.-Y. Cheng, P.M. Firdausi, and D. Prayogo, "High-performance concrete compressive strength prediction using Genetic Weighted Pyramid Operation Tree (GWPOT)", Eng. Appl. Artif. Intel., 2014, 29, pp. 104-113.

[18] M.-Y. Cheng, D. Prayogo, Y.-H. Ju, Y.-W. Wu, and S. Sutanto, "Optimizing mixture properties of biodiesel production using genetic algorithm-based evolutionary support vector machine", Int. J. Green Energy, 2016, 13, (15), pp. 1599-1607.

[19] M.-Y. Cheng, D. Prayogo, and Y.-W. Wu, "Novel Genetic AlgorithmBased Evolutionary Support Vector Machine for Optimizing HighPerformance Concrete Mixture", J. Comput. Civil Eng., 2014, 28, (4), pp. 06014003.

[20] M.-Y. Cheng, D.K. Wibowo, D. Prayogo, and A.F.V. Roy, "Predicting productivity loss caused by change orders using the evolutionary fuzzy support vector machine inference model", J. Civil Eng. Manag., 2015, 21, (7), pp. 881-892.

[21] M.-Y. Cheng and D. Prayogo, "Symbiotic Organisms Search: A new metaheuristic optimization algorithm", Comput. Struct., 2014, 139, pp. 98-112.

[22] D. Prayogo, M.-Y. Cheng, and H. Prayogo, "A Novel Implementation of Nature-inspired Optimization for Civil Engineering: A Comparative Study of Symbiotic Organisms Search", Civil Engineering Dimension, 2017, 19, (1), pp. 36-43.

[23] M.-Y. Cheng, C.-K. Chiu, Y.-F. Chiu, Y.-W. Wu, Z.-L. Syu, D. Prayogo, and C.-H. Lin, "SOS optimization model for bridge life cycle risk evaluation and maintenance strategies", J. Chin. Inst. Civil Hydraul. Eng., 2014, 26, (4), pp. 293-308.

[24] M.-Y. Cheng and D. Prayogo, "Modeling the permanent deformation behavior of asphalt mixtures using a novel hybrid computational intelligence", ISARC 2016 - 33rd Int. Symp. on Automation and Robotics in Construction, Auburn, USA, 2016, pp. 1009-1015.

[25] M.-Y. Cheng, D. Prayogo, and D.-H. Tran, "Optimizing MultipleResources Leveling in Multiple Projects Using Discrete Symbiotic Organisms Search", J. Comput. Civil Eng., 2016, 30, (3), pp. 04015036.

[26] D.-H. Tran, M.-Y. Cheng, and D. Prayogo, "A novel Multiple Objective Symbiotic Organisms Search (MOSOS) for time-cost-labor utilization tradeoff problem", Know.-Based Syst., 2016, 94, pp. 132145 .

[27] A. Askarzadeh, "A novel metaheuristic method for solving constrained engineering optimization problems: Crow search algorithm", Comput. Struct., 2016, 169, pp. 1-12.

[28] L.J. Li., Z.B. Huang, and F. Liu, "A heuristic particle swarm optimization method for truss structures with discrete variables", Comput. Struct., 2009, 87, pp. 435-443. 